This is the peer reviewed version of the following article: Francesconi, M..G., Bennett, M...., Dobson, I. and Benoit, D..M. (2021), Utilisation of CO2 as "Structure Modifier" of Inorganic Solids. Chem. Eur. J.. Accepted Author Manuscript, which has been published in final form at https://doi.org/10.1002/chem.202103608. This article may be used for non-commercial purposes in accordance with Wiley Terms and Conditions for Use of Self-Archived Versions. This article may not be enhanced, enriched or otherwise transformed into a derivative work, without express permission from Wiley or by statutory rights under applicable legislation. Copyright notices must not be removed, obscured or modified. The article must be linked to Wiley's version of record on Wiley Online Library and any embedding, framing or otherwise making available the article or pages thereof by third parties from platforms, services and websites other than Wiley Online Library must be prohibited.

\title{
Utilisation of $\mathrm{CO}_{2}$ as "Structure Modifier" of Inorganic Solids
}

\author{
M. J. Bennett, ${ }^{[a]}$ I. Dobson, ${ }^{[a]}$ D. M. Benoit, ${ }^{*[b]}$ and M. G. Francesconi* ${ }^{*[]]}$
}

Abstract: Utilisation of $\mathrm{CO}_{2}$ as a chemical reagent is challenging, due to the molecule's inherent chemical stability. However, $\mathrm{CO}_{2}$ reacts promptly at high temperature $\left(\sim 1000^{\circ} \mathrm{C}\right)$ with alkaline-earth oxides to form carbonates and such reactions are used towards capture and re-utilisation. In this work, this concept is extended and $\mathrm{CO}_{2}$ is utilised as a reagent to modify the crystal structure of mixed-metal inorganic solids. Modification of the crystal structure is a "tool" used by materials scientists to tailor the physical property of solids. $\mathrm{CO}_{2}$ gas was reacted with several isostructural mixed-metal oxides $\mathrm{Sr}_{2} \mathrm{CuO}_{3}, \mathrm{Sr}_{1.8} \mathrm{Ba}_{0.2} \mathrm{CuO}_{3}$ and $\mathrm{Ba}_{2} \mathrm{PdO}_{3}$. These oxides are carefully selected to show anion vacancies in their crystal structure, to act as host sites for $\mathrm{CO}_{2}$ molecules, leading to the formation of carbonate anions, $\left(\mathrm{CO}_{3}\right)^{2-}$. The corresponding oxide carbonates were formed successfully and the favourable formation of $\mathrm{SrCO}_{3}$ as secondary phase was minimised via an innovative, yet simple synthetic procedure involving alternating of $\mathrm{CO}_{2}$ and air. We also derived a simple model to predict the kinetics of the reactions for the cuprates, using first-principles density functional theory and assimilating the reaction to a gas-surface process.

\section{Introduction}

Materials are at the core of our ever more high-technology society, with the impact of new materials discovery felt throughout on a daily basis. Inorganic materials in particular, have their role in many innovative applications and thus discovery of new inorganic materials has allowed access to new technologies. For example, inorganic materials with semiconducting properties started the computer revolution and now are investigated as photocatalytic materials for environmental applications, superconducting materials could be part of future energy saving plans and are currently key components in Magnetic Resonance Imaging (MRI) instrument and quantum computers. A wide range of imaginative synthetic routes has led not only to brand new chemical classes but also to the modification of structure and properties of known materials in order to target specific applications. In this work, we propose the use of $\mathrm{CO}_{2}$ gas as a tool to modify the structure of selected materials. If such synthetic route is established among materials chemists, it will offer an additional approach to the synthesis of inorganic materials with the benefit of utilising a gas normally considered harmful to the environment. Increasing concerns

[a] M. J. Bennett, I. Dobson, M. G. Francesconi

Department of Chemistry and Biochemistry University of Hull

Cottingham Road, Hull HU6 7RX (UK)

E-mail:m.g.francesconi@hull.ac.uk

[b] D. M. Benoit

Department of Physics and Mathematics

University of Hull

Cottingham Road, Hull HU6 7RX (UK)

E-mail: d.benoit@hull.ac.uk

$\square$ Supporting information for this article is available on the WWW under https://doi.org/10.1002/chem.202103608 have risen over the link between $\mathrm{CO}_{2}$ emissions and rising global temperatures. ${ }^{[1,2]}$

Interaction of inorganic solids with $\mathrm{CO}_{2}$ gas is being considered in relation to $\mathrm{CO}_{2}$ capture and utilisation. ${ }^{[3]}$ Zeolites and metal-organic frameworks (MOFs) for example have porous structures which allow them to store quantities of $\mathrm{CO}_{2}$ gas from emissions, mostly via physisorption. ${ }^{[4-7]}$ Alkaline earth metal oxides $\mathrm{MO}(\mathrm{M}=\mathrm{Ca}$ and $\mathrm{Mg})$ have also been investigated for the capture $\mathrm{CO}_{2}$ via the formation of metal carbonates $\mathrm{MCO}_{3}{ }^{[8,9]}$ $\mathrm{CO}_{2}$ reacts readily with alkaline earth metal oxides to form carbonates, due to the strong affinity of the $\mathrm{M}-\mathrm{O}$ bonds for $\mathrm{CO}_{2}$.

In this work, we extend the use of $\mathrm{CO}_{2}$ for the formation of binary carbonates to the use of $\mathrm{CO}_{2}$ as reagent to modify the crystal structures of mixed-metal oxides. To obtain a proof-of concept for our method, we have chosen a class of materials, which contain alkaline earth metals and show vacancies in their crystal structures. These vacancies act as hosts for the $\mathrm{CO}_{2}$ which then binds to one oxide within the structure to form a carbonate. This process leads to the formation of oxidecarbonates as well as a structural rearrangement, leading to different compounds (oxide-carbonates) with a different crystal structure, albeit related to that of the starting material.

Compounds with general formula $\mathrm{A}_{2} \mathrm{BO}_{3} \quad(A=$ metal 1 , $\mathrm{B}=$ metal 2) or $\mathrm{AO}\left(\mathrm{ABO}_{3}\right)_{n}$ show anion vacancies. Their crystal structures relate to the $n=1$ series of Ruddlesden-Popper phases, $\mathrm{A}_{2} \mathrm{BO}_{4}$, containing 1 perovskite-type layer $\left(\mathrm{ABO}_{3}\right)$ interleaved by $1 \mathrm{NaCl}$-type layer (AO). The anion-deficiency in $\mathrm{A}_{2} \mathrm{BO}_{3}$ compounds when compared with the $\mathrm{A}_{2} \mathrm{BO}_{4}$ series, derives from the absence of the two equatorial oxide anions in the coordination sphere of transition metal $B$. In $\mathrm{A}_{2} \mathrm{BO}_{3}(\mathrm{~A}=\mathrm{Ca}$, $\mathrm{Sr}, \mathrm{Ba} ; \mathrm{B}=\mathrm{Cu}, \mathrm{Pd}$ ) the $\mathrm{B}$ cation is coordinated by the oxide anions in a square planar manner with each $\mathrm{B}-\mathrm{O}$ square linked to another via one of its corners to form linear 1D chains 
(Figure 1). The anion vacancies, which are used as "host sites" for $\mathrm{CO}_{2}$ molecules, are ordered along these chains. $\mathrm{A}_{2} \mathrm{BO}_{3}(\mathrm{~A}=\mathrm{Ca}$, $\mathrm{Sr}, \mathrm{Ba} ; \mathrm{B}=\mathrm{Cu}, \mathrm{Pd}$ ) compounds have been used as "hosts" for extra anions and, as a consequence, a structural rearrangement had taken place. Oxide insertion in $\mathrm{Sr}_{2} \mathrm{CuO}_{3}$ was carried out by Lobo et al. using high pressure $\mathrm{O}_{2}$ gas and resulted in the formation of the $\mathrm{Sr}_{2} \mathrm{CuO}_{3+x}$ series with superconducting properties. ${ }^{[10,11]}$ The crystal structure changed from orthorhombic to tetragonal.

Extensive research was carried out on the fluoride insertion/ substitution in $\mathrm{Sr}_{2} \mathrm{CuO}_{3}$ and led to formation of the oxidefluoride, $\mathrm{Sr}_{2} \mathrm{CuO}_{2} \mathrm{~F}_{2+\delta},(0 \leq \delta \leq 0.35) .^{[12,13]}$ In the fluorination of $\mathrm{Sr}_{2} \mathrm{CuO}_{3}$ towards $\mathrm{Sr}_{2} \mathrm{CuO}_{2} \mathrm{~F}_{2+\delta}, 1$ oxide anion was replaced by 2 fluorides and extra fluoride anions were inserted into the interstitial sites within the crystal structure. The coordination of the copper cation changed from 4, in $\mathrm{Sr}_{2} \mathrm{CuO}_{3}$, to 6 , in $\mathrm{Sr}_{2} \mathrm{CuO}_{2} \mathrm{~F}_{2+\delta}$, due to the increased anion number. The crystal system also changed from body centred orthorhombic to primitive tetragonal and the extra fluoride anion, $\delta$, caused a 2 $+/ 3+$ mixed oxidation state of the copper cation as charge compensation mechanism. The structure of $\mathrm{Sr}_{2} \mathrm{CuO}_{2} \mathrm{~F}_{2+\delta}$ is classified as an anion-deficient $\mathrm{La}_{2} \mathrm{CuO}_{4}$-type $\left(\mathrm{K}_{2} \mathrm{NiF}_{4}\right.$-type $)$ structure. In practice, the fluorination process "filled up" the anion vacancies. Within this series, the compound $\mathrm{Sr}_{2} \mathrm{CuO}_{2} \mathrm{~F}_{2.3}(\delta$ $\approx 0.3$ ) shows high $\mathrm{T}_{\mathrm{c}}$ superconductivity ( $\mathrm{Tc} \sim 46 \mathrm{~K}$ ).

Compounds of general formula $\mathrm{Sr}_{2-\mathrm{x}} \mathrm{Ba}_{\mathrm{x}} \mathrm{CuO}_{3}$, derived from $\mathrm{Sr}_{2} \mathrm{CuO}_{3}$ via isovalent substitution of $\mathrm{Sr}^{2+}$ with $\mathrm{Ba}^{2+}$ were also fluorinated and led to the formation of oxide-fluorides adopting the "full" $\mathrm{K}_{2} \mathrm{NiF}_{4}$-type structure. ${ }^{[13-15]}$

$\mathrm{Ba}_{2} \mathrm{PdO}_{3}$ is isostructural to $\mathrm{Sr}_{2} \mathrm{CuO}_{3}$ and was reported to undergo fluorination to form the oxide-fluoride $\mathrm{Ba}_{2} \mathrm{PdO}_{2} \mathrm{~F}_{2}{ }^{[16,17]}$ The coordination of $\mathrm{Pd}^{2+}$ remains square planar, but, instead of one-dimensional chains of $\mathrm{Pd}-\mathrm{O}$ squares, there are two-dimensional planes of $\mathrm{Pd}-\mathrm{O}$ squares in $\mathrm{Ba}_{2} \mathrm{PdO}_{2} \mathrm{~F}_{2}$. The structure of $\mathrm{Ba}_{2} \mathrm{PdO}_{2} \mathrm{~F}_{2}$ is classified as a $\mathrm{Nd}_{2} \mathrm{CuO}_{4}$-type structure.

In this work we use these finding on anion insertion in $\mathrm{A}_{2} \mathrm{BO}_{3}(\mathrm{~A}=\mathrm{Ca}, \mathrm{Sr}, \mathrm{Ba} ; \mathrm{B}=\mathrm{Cu}, \mathrm{Pd})$ to obtain a proof-of-concept that
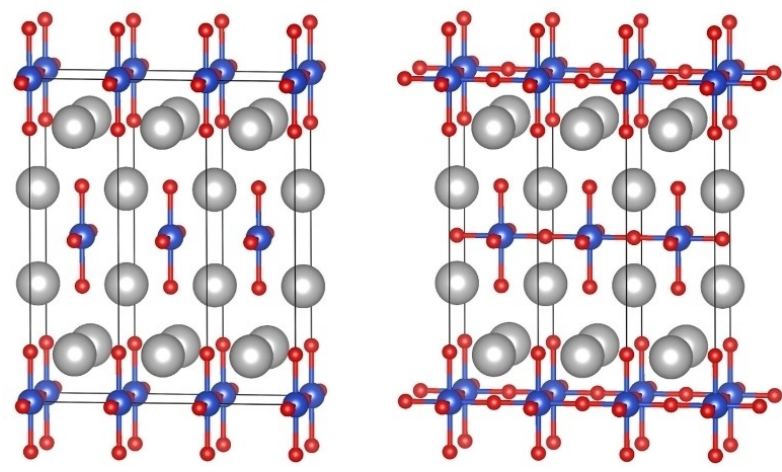

Figure 1. The crystal structure of $\mathrm{A}_{2} \mathrm{BO}_{4}$ left, and $\mathrm{A}_{2} \mathrm{BO}_{3}$, right with $\mathrm{A}=\mathrm{Ca}, \mathrm{Sr}$ $\mathrm{Ba}$ and $\mathrm{B}=\mathrm{Cu}, \mathrm{Pd}$. The silver spheres represent the cation $\mathrm{A}$ and the red spheres represent the anions $\mathrm{O}_{2}$. The blue squares are the $\mathrm{B}$ cation, blue spheres with the $\mathrm{B}-\mathrm{O}$ coordination bonds showing either square-planar of octahedral coordination.
$\mathrm{CO}_{2}$ gas can be hosted within the vacancies of the crystal structure and give oxide carbonates, as well as inducing a structural rearrangement related to those observed for the fluorination of these materials.

Specifically, here, we obtained $\mathrm{Sr}_{2} \mathrm{CuO}_{2}\left(\mathrm{CO}_{3}\right)$ $\mathrm{Sr}_{1.8} \mathrm{Ba}_{0.2} \mathrm{CuO}_{2}\left(\mathrm{CO}_{3}\right), \quad \mathrm{Sr}_{1.75} \mathrm{Ca}_{0.25} \mathrm{CuO}_{2}\left(\mathrm{CO}_{3}\right)$ and $\mathrm{Ba}_{11} \mathrm{Pd}_{11} \mathrm{O}_{20}\left(\mathrm{CO}_{3}\right)_{2}$ via the insertion of $\mathrm{CO}_{2}$ in the respective starting oxides $\mathrm{Sr}_{2} \mathrm{CuO}_{3}, \mathrm{Sr}_{1.8} \mathrm{Ba}_{0.2} \mathrm{CuO}_{3}, \mathrm{Sr}_{1.5} \mathrm{Ca}_{0.5} \mathrm{CuO}_{3}$ and $\mathrm{Ba}_{2} \mathrm{PdO}_{3}$.

Furthermore, we investigate the kinetic constants of the reactions between $\mathrm{A}_{2} \mathrm{CuO}_{3}(\mathrm{~A}=\mathrm{Ca}, \mathrm{Sr}, \mathrm{Ba})$ and $\mathrm{CO}_{2}$. We also formulate a simple computational model that relies on insights gained from the reaction of the corresponding metal oxides (AO) with $\mathrm{CO}_{2}$ to form carbonates. Those have been previously investigated using theoretical methods for both surface ${ }^{[18,19]}$ and bulk calculations ${ }^{[20,21]}$.

\section{Experimental Section}

Preparation of $\mathrm{Sr}_{2-x} \mathrm{~A}_{\mathrm{x}} \mathrm{CuO}_{3}(\mathrm{~A}=\mathrm{Ca}$ and $\mathrm{Ba})$ : The preparation of $\mathrm{Sr}_{2} \mathrm{CuO}_{3}$ was carried out via a high temperature ceramic method using polycrystalline $\mathrm{ACO}_{3}(\mathrm{~A}=\mathrm{Sr}, \mathrm{Ba}$ and $\mathrm{Ca}$ ) (98.5\% BDH GPR), and $\mathrm{CuO}(96.0 \% \mathrm{BDH} \mathrm{GPR}){ }^{[22]}$ All reagents were stored in an oven at approximately $100^{\circ} \mathrm{C}$ to prevent moisture contamination. The reagents were mixed in a stoichiometric ratio with acetone to produce a dispersed homogenous mixture. This mixture was then placed into an aluminium crucible that was inserted into a box furnace and heated to $1000^{\circ} \mathrm{C}$ for $14 \mathrm{~h}$ in static air. Intermediate regrinding and reheating cycles were performed until high purity products $(>99 \%)$ were achieved. $\mathrm{Sr}_{1.5} \mathrm{Ca}_{0.5} \mathrm{CuO}_{3}$ was prepared via the same procedure as $\mathrm{Sr}_{2} \mathrm{CuO}_{3}$ except with the reagent mixture compressed into pellets before being heated. $\mathrm{Sr}_{1.8} \mathrm{Ba}_{0.2} \mathrm{CuO}_{3}$ was prepared in the same way as $\mathrm{Sr}_{1.5} \mathrm{Ca}_{0.5} \mathrm{CuO}_{3}$ except that it was heated under $\mathrm{O}_{2}$ gas. These high-purity oxides were then reacted with $\mathrm{CO}_{2}$ gas.

Preparation of $\mathrm{Ba}_{2} \mathrm{PdO}_{3}: \mathrm{Ba}_{2} \mathrm{PdO}_{3}$ was prepared via a two-step heating process. Firstly, $\mathrm{PdO}$ and $\mathrm{BaCO}_{3}$ (99\% Lancaster) were mixed in a stoichiometric ratio with acetone to produce a dispersed homogenous mixture. This mixture was firstly heated to $700^{\circ} \mathrm{C}$ for $12 \mathrm{~h}$ to allow $\mathrm{PdO}$ to react with $\mathrm{BaO}$, as well as to prevent $\mathrm{PdO}$ reducing to $\mathrm{Pd}$ metal. ${ }^{[23]}$ Afterwards a second heating cycle at $1150^{\circ} \mathrm{C}$ for $50 \mathrm{~h}$ was carried out.

Reactions with $\mathrm{CO}_{2}$ : All the reactions between the solid compounds and $\mathrm{CO}_{2}$ gas were carried out in a thermal gravimetric analysis (TGA) instrument, to monitor the reaction in situ. Pre-weighted samples of $\mathrm{A}_{2} \mathrm{BO}_{3}(\mathrm{~A}=\mathrm{Sr}, \mathrm{Ba}$ and $\mathrm{B}=\mathrm{Pd}, \mathrm{Cu})$ were placed into an alumina crucible then inserted into the TGA furnace chamber. The samples were initially heated to $1000^{\circ} \mathrm{C}$ under compressed air $\left(\mathrm{O}_{2}\right)$ $\mathrm{N}_{2}$ mixture). The temperature was then maintained at $1000^{\circ} \mathrm{C}$ for 2 minutes to reach equilibrium before the gas flow was changed to pure $\mathrm{CO}_{2}$. After a 15 -minute isotherm at $1000^{\circ} \mathrm{C}$, the gas flow was switched back to compressed air for the samples to cool to room temperature.

The TGA instrument was a Mettler Toledo TGA/DSC 1 Star System and a GC100 gas controller, which showed the weight of the sample changing at different temperatures and gases. All gas flow rates were maintained at a value of $100 \mathrm{ml} / \mathrm{min}$ and the temperature ramp rate was at $100^{\circ} \mathrm{C} / \mathrm{min}$. The overall change in weight from the reaction, was determined from the difference between the samples weight at $1000^{\circ} \mathrm{C}$ under air, to the weight of the sample after the reaction with $\mathrm{CO}_{2}$. The procedure used to calculate the $\left(\mathrm{CO}_{3}\right)^{2-}$ content in $\mathrm{Sr}_{2} \mathrm{CuO}_{2}\left(\mathrm{CO}_{3}\right)$ was based on the ratio of the 
starting mass to that of the residue mass. The accuracy of the TGA balance is given at $\pm 0.005 \mathrm{mg}$.

Powder X-ray diffraction: Powder X-Ray Diffraction (PXRD) was performed on a PANalytical Empyrean Series 2 Diffractometer operating $\mathrm{CuK}_{\alpha 1}(\lambda=1.54056 \AA)$ radiation. Samples were scanned using an automatic slit at a step size of $0.026^{\circ}$ and a net time per step of $304.2 \mathrm{~s}$ at a power setting of $40 \mathrm{kV}$ and $30 \mathrm{~mA}$. A $2 \theta^{\circ}$ range of $5-80^{\circ}$ was used. For collection of data to be used for Rietveld refinements, the scan range was carried out from $5-120^{\circ}$ with a $1 / 4^{\circ}$ fixed slit at a step size of $0.026^{\circ}$ and a net time per step of $1221.45 \mathrm{~s}$ using a power setting of $45 \mathrm{kV}$ and $40 \mathrm{~mA}$. Subsequent analysis was performed either in HighScore Plus 1 using the PDF-2 2012 database of powder patterns. ${ }^{[24]}$ The GSAS suite of programs via the EXPGUI software was used for Rietveld refinements. ${ }^{[25,26]}$ The background was initially modelled using the Cosine Fourier series with twelve terms. The multi-term Simpson's rule integration of the pseudo-Voigt was used in order to model the peaks shapes within the pattern. ${ }^{[27,28]}$

Theoretical approach to study the solid-gas reactions: The theoretical modelling of the interaction between $\mathrm{CO}_{2}$ and the $\mathrm{AO}$ $(\mathrm{A}=\mathrm{Ca}, \mathrm{Sr}$ and $\mathrm{Ba})$ surfaces was carried out using the ORCA suite of programs (version 3.0.3). ${ }^{[29]}$ The Perdew-Burke-Ernzerhof (PBE) exchange correlation functional was used with a resolution of identity approximation for the Coulomb interactions. ${ }^{[30,31]}$ The valence electrons were represented with a triple zeta valence polarised def2-TZVP basis set along with a compatible def2-TZVP/J auxiliary basis set. ${ }^{[32,33]}$ The TightOpt criteria implemented in ORCA was used to stop the geometry optimization at a total energy change of $1<10^{-6}$ Eh, respectively. Dispersion forces for each system were included using the Becke-Johnson damping D3BJ method. ${ }^{[34,35]}$

A surface model of the $\mathrm{AO}(\mathrm{A}=\mathrm{Ba}, \mathrm{Ca}$ and $\mathrm{Sr})$ oxides were prepared using the first top two layers of the reported crystal structures. ${ }^{[36}$ Figure 2 shows a representation of the AO surface consisting of 18 atoms prepared from the original AO crystal structure.

All AO metal oxides considered have a $\mathrm{NaCl}$ type structure. To obtain the required binding energy values and optimised struc tures, a $\mathrm{CO}_{2}$ molecule was placed over the metal oxide and allowed to optimise towards forming a carbonate. All calculations were performed on the high-performance computer (HPC), Viper, at the University of Hull.

\section{Results and Discussion}

Reaction between $\mathrm{Sr}_{2} \mathrm{CuO}_{3}$ and $\mathrm{CO}_{2}$

In this work, $\mathrm{Sr}_{2} \mathrm{CuO}_{3}$ was chosen as a paradigm starting material for "hosting" $\mathrm{CO}_{2}$ in the vacancies of its crystal structure to lead to $\mathrm{Sr}_{2} \mathrm{CuO}_{2}\left(\mathrm{CO}_{3}\right)$, in order to demonstrate that $\mathrm{CO}_{2}$ can be used as a reagent to modify the composition and

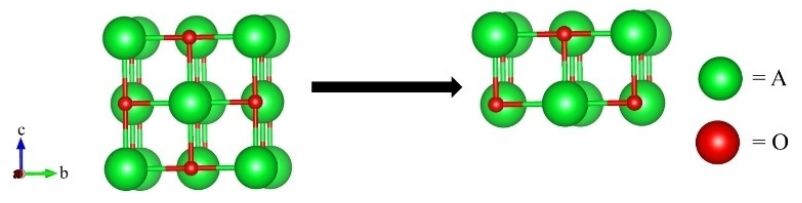

Figure 2. The crystal structure of an $\mathrm{AO}$ compound $(\mathrm{A}=\mathrm{Ca}, \mathrm{Sr}$ and $\mathrm{Ba})$ is on the left, with the reduced cluster on the right. crystal structure of materials. In this case, the starting materials are oxides, which, via direct reaction with $\mathrm{CO}_{2}$, give oxide carbonates. The crystal structure of the parent and the resulting compounds are closely related. $\mathrm{Sr}_{2} \mathrm{CuO}_{2}\left(\mathrm{CO}_{3}\right)$ was originally reported by $\mathrm{Babu}$ et al. as an intermediate during the formation of $\mathrm{Sr}_{2} \mathrm{CuO}_{3}$ from $\mathrm{SrCO}_{3}$ and $\mathrm{CuO}^{[37]}$ Later, Miyazaki et al. prepared a purer phase by reacting $\mathrm{SrCO}_{3}$ and $\mathrm{CuO}$ with varying mixtures of $\mathrm{O}_{2}$ and $\mathrm{CO}_{2}$ gases at varying pressures. ${ }^{[38]}$

We aimed at studying the feasibility of $\mathrm{CO}_{2}(\mathrm{~g})$ as a reagent to prepare inorganic solids. Therefore, we chose a known starting oxide and a known product but altered the synthesis procedure in order to focus on a direct reaction between the starting oxide and $\mathrm{CO}_{2}(\mathrm{~g})$. We carried out direct reactions of $\mathrm{Sr}_{2} \mathrm{CuO}_{3}$ with $\mathrm{CO}_{2}(\mathrm{~g})$ under several different conditions to identify the route leading to the purest $\mathrm{Sr}_{2} \mathrm{CuO}_{2}\left(\mathrm{CO}_{3}\right)$. In the first sets of reactions the reaction temperature was varied between 500 and $1000^{\circ} \mathrm{C}$ and the dwell time from 5 to 120 minutes. All the steps (heating, dwell and cooling) were carried out under $\mathrm{CO}_{2}$ gas and the products were mixtures of $\mathrm{SrCO}_{3}$, and $\mathrm{Sr}_{2} \mathrm{CuO}_{2}\left(\mathrm{CO}_{3}\right)$. The formation of $\mathrm{SrCO}_{3}$ as secondary phase seemed to occur in all the reactions trialled at different temperatures. In particular, the formation of $\mathrm{SrCO}_{3}$ seems to start at the beginning of the process, during the heating step.

To minimise the formation of the secondary phase, $\mathrm{SrCO}_{3}$ the heating step was carried out under an air flow instead of $\mathrm{CO}_{2} \cdot \mathrm{CO}_{2}$ gas was then introduced in the dwell step once the reaction temperature had been reached. In the cooling step, the gas was then switched back to air, again to minimise formation of $\mathrm{SrCO}_{3}$. Thermo Gravimetric Analysis (TGA) was used to monitor the reaction of $\mathrm{CO}_{2}$ with $\mathrm{Sr}_{2} \mathrm{CuO}_{3}$. The reaction was determined to occur when a weight increase appeared in the TGA graph (Figure 3). This weight increase shows uptake of $\mathrm{CO}_{2}$ and starts at $\mathrm{T}=1000^{\circ} \mathrm{C}$ (Figure 3). After trialling several reaction times, the dwell step was determined to be $\mathrm{T}=1000^{\circ} \mathrm{C}$ for 15 minutes. TGA shows that the sample has taken up $16 \%$ $\mathrm{CO}_{2}$ by weight.

PXRD patterns showed that $\mathrm{Sr}_{2} \mathrm{CuO}_{2}\left(\mathrm{CO}_{3}\right)$ was the main phase with small amounts of $\mathrm{SrCO}_{3}$ impurity. A two-phase refinement of PXRD data was carried out, using the structural model of $\mathrm{Sr}_{2} \mathrm{CuO}_{2}\left(\mathrm{CO}_{3}\right)$ by Babu et al. ${ }^{[37]}(\mathrm{P} 4 / \mathrm{mmm} \mathrm{A}=3.9033(2) \AA$ ; $c=7.4925(4) \AA$ ) and model by Antao et al. for $\mathrm{SrCO}_{3}{ }^{[39]}$ The

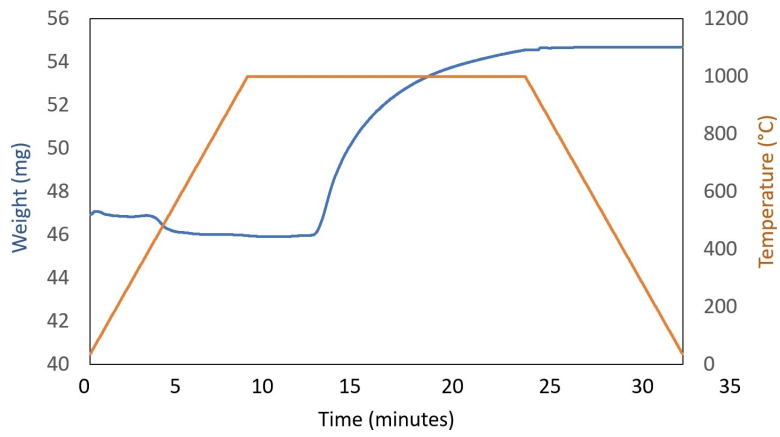

Figure 3. TGA curve showing an increase in the weight of the sample $\mathrm{Sr}_{2} \mathrm{CuO}_{3}$ as $\mathrm{CO}_{2}$ is introduced at $1000^{\circ} \mathrm{C}$ forming $\mathrm{Sr}_{2} \mathrm{CuO}_{2}\left(\mathrm{CO}_{3}\right)$. 
PXRD pattern resulting from Rietveld refinement is shown in Figure 4 a. The unit cell parameters, $A=3.903$ (4) $\AA$; $c=7.497(1)$ $\AA)$, are in agreement with the literature, the $\mathrm{R}$ values are $R_{p}=$ $12.4 \%, R_{w p}=17.6 \%{ }^{[37]}$ The weight percentages of $\mathrm{Sr}_{2} \mathrm{CuO}_{2}\left(\mathrm{CO}_{3}\right)$ and $\mathrm{SrCO}_{3}$ are $85.5( \pm 0.1) \% \mathrm{Sr}_{2} \mathrm{CuO}_{2}\left(\mathrm{CO}_{3}\right)$ and $14.6 \pm 0.2 \%$ $\mathrm{SrCO}_{3}$. Structural data are included in Supplemental Information (Table S1).

The presence of $\mathrm{SrCO}_{3}$ clearly indicate a degree of decomposition of $\mathrm{Sr}_{2} \mathrm{CuO}_{3}$ during the reaction with $\mathrm{CO}_{2}$, however, we could not find sufficiently clear evidence of a copper-containing secondary phase. We can only infer that a small percentage of copper-containing secondary phase is present but could not be detected by PXRD, possibly because of reactivity with moisture resulting in broadening of the diffraction peaks.

A structural rearrangement accompanies the formation of $\mathrm{Sr}_{2} \mathrm{CuO}_{2}\left(\mathrm{CO}_{3}\right)$. The $\mathrm{CO}_{2}$ molecule form a carbonate anion via a bond with an oxide anion belonging to the $\mathrm{SrCuO}_{3}$ structure. The carbonate anion is located in the crystal structure vacancies and this induces a structural rearrangement which the unit cell transitioning from the orthorhombic crystal system to the tetragonal one. The unit cell of $\mathrm{Sr}_{2} \mathrm{CuO}_{2}\left(\mathrm{CO}_{3}\right)$ is shown in the insert of Figure 4 (top right). The structural rearrangement occurring here is reminiscent of that identified for the fluorination of $\mathrm{Sr}_{2} \mathrm{CuO}_{3}$ to $\mathrm{Sr}_{2} \mathrm{CuO}_{2} \mathrm{~F}_{2+\delta} \cdot{ }^{[13]}$

To test a more general applicability for the use of $\mathrm{CO}_{2}$ as "structure modifier", we chose other mixed-metal compounds with stoichiometry and crystal structure related to $\mathrm{Sr}_{2} \mathrm{CuO}_{3}$, i.e., $\mathrm{Ca}_{2} \mathrm{CuO}_{3}, \mathrm{Sr}_{1.8} \mathrm{Ba}_{0.2} \mathrm{CuO}_{3}$ and $\mathrm{Ba}_{2} \mathrm{PdO}_{3}$.

\section{Reactions of $\mathrm{Ca}_{2} \mathrm{CuO}_{3}, \mathrm{Sr}_{1.5} \mathrm{Ca}_{0.5} \mathrm{CuO}_{3}$ and $\mathrm{Sr}_{1.8} \mathrm{Ba}_{0.2} \mathrm{CuO}_{3}$ with} $\mathrm{CO}_{2}$

$\mathrm{Ca}_{2} \mathrm{CuO}_{3}(\mathrm{Immm}, a=12.25(2), B=3.789(8) \text { and } c=3.259(3) \AA)^{[40]}$ was reacted with $\mathrm{CO}_{2}$ in the same conditions as $\mathrm{Sr}_{2} \mathrm{CuO}_{3}$, however no formation of oxide-carbonate was obtained. The reason for this lack of reactivity may be found in the difference in the size of the vacancies between $\mathrm{Sr}_{2} \mathrm{CuO}_{3}$ and $\mathrm{Ca}_{2} \mathrm{CuO}_{3}$. In fact, the size of the anion vacancies in $\mathrm{Sr}_{2} \mathrm{CuO}_{3}$ is $3.50(2) \AA$ (based on the distance between the $\mathrm{Cu}$ atoms in the $b$ direction), whereas the size of the anion vacancies in $\mathrm{Ca}_{2} \mathrm{CuO}_{3}$ is approximately $3.25(1) \AA$. The kinetic diameter of $\mathrm{CO}_{2}$ is $3.3 \AA^{[41]}$ hence the anion vacancies in $\mathrm{Ca}_{2} \mathrm{CuO}_{3}$ may prove too small to host the $\mathrm{CO}_{2}$ molecule. $\mathrm{Ca}_{2} \mathrm{CuO}_{2}\left(\mathrm{CO}_{3}\right)$ was actually reported in the literature but its preparation required extreme conditions including a high pressure of $6 \mathrm{GPa}$, at $1300^{\circ} \mathrm{C}$ and a $\mathrm{AgO}$ flux. ${ }^{[42]}$

To explore this hypothesis, we modified the size of the anion vacancies in $\mathrm{Sr}_{2} \mathrm{CuO}_{3}$ via isovalent substitutions. Specifically, $\mathrm{Sr}_{1.5} \mathrm{Ca}_{0.5} \mathrm{CuO}_{3}$ was selected as a prototype sample to show anion vacancies smaller than those in $\mathrm{Sr}_{2} \mathrm{CuO}_{3}$ and $\mathrm{Sr}_{1.8} \mathrm{Ba}_{0.2} \mathrm{CuO}_{3}$ as a prototype sample to show anion vacancies larger than those in $\mathrm{Sr}_{2} \mathrm{CuO}_{3}$.

$\mathrm{Sr}_{1.5} \mathrm{Ca}_{0.5} \mathrm{CuO}_{3}$ was reacted 15,60 and 90 minute at $1000^{\circ} \mathrm{C}$ under $\mathrm{CO}_{2}$. The PXRD pattern for the 90-minute reaction showed that a $\mathrm{Sr}_{2} \mathrm{CuO}_{2}\left(\mathrm{CO}_{3}\right)$-type phase had formed, however other phases were present, specifically $\mathrm{SrCO}_{3}$ and $\mathrm{SrCaCuO}_{3}$. A three-phase Rietveld refinement was carried out. ${ }^{[43,44]}$ In the refinements the model of $\mathrm{Sr}_{2} \mathrm{CuO}_{2}\left(\mathrm{CO}_{3}\right)$ reported by Babu et al. was used for the calcium-copper oxide carbonate. The calcium content was initially set at $\mathrm{x}=0.5$ to reflect the stoichiometric ratio of the reagents.

For the refinement the background was modelled using the Cosine Fourier series with twelve terms. The multi-term Simpson's rule integration of the pseudo-Voigt was used in order to model the peaks shapes within for all phases. ${ }^{[4,46]}$ The parameters refined were the cell parameters and the scale factors for all three-phases. The $\mathrm{U}_{\text {iso }}$ and the atomic coordinates for the strontium and calcium were constrained with each other when refined. The Lorentzian anisotropic strain broadening was also refined as well. The fractional occupancy between the strontium and calcium was also refined within the oxide carbonate phase. The refinement of the occupancies showed that the formula of the sample was actually $\mathrm{Sr}_{1.75} \mathrm{Ca}_{0.25} \mathrm{CuO}_{2}\left(\mathrm{CO}_{3}\right)$.

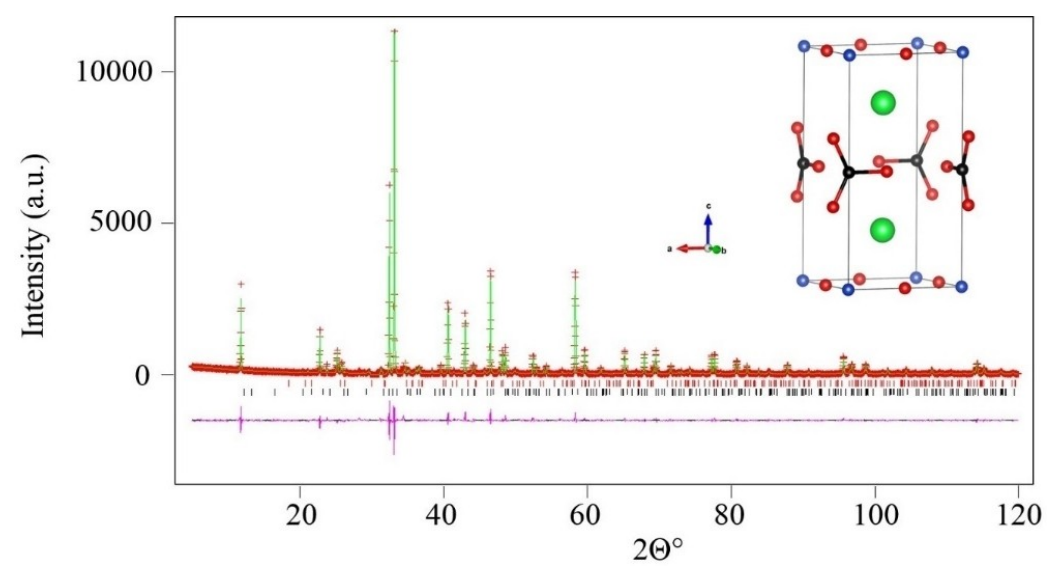

Figure 4. Rietveld refinement profile for $\mathrm{Sr}_{2} \mathrm{CuO}_{2}\left(\mathrm{CO}_{3}\right)$, showing the observed (red crosses), calculated (green) and difference (purple) patterns. The reflections belonging to $\mathrm{SrCO}_{3}$ are marked with $\left(^{*}\right)$ and the red ticks. Inset: Crystal structure of $\mathrm{Sr}_{2} \mathrm{CuO}_{2}\left(\mathrm{CO}_{3}\right)$. The green spheres represent $\mathrm{Sr}^{2+}$ cations, the blue spheres $\mathrm{Cu}^{2+}$ cations and the red spheres $\mathrm{O}^{2-}$ anions. 
This is possibly due to the formation of the secondary phase containing $\mathrm{Sr}, \mathrm{Ca}$ and $\mathrm{Cu}$ for which the refinement of the strontium and calcium occupancies gave a 1:1 stoichiometric ratio hence the $\mathrm{SrCaCuO}_{3}$ formula. The refinement is shown in Figure 5.

The $\mathrm{R}$-values for this refinement were determined as $\mathrm{R}_{\mathrm{wp}}=$ $12.9 \%$ and $\mathrm{Rp}=9.3$. The structural data of $\mathrm{Sr}_{1.75} \mathrm{Ca}_{0.25} \mathrm{CuO}_{2}\left(\mathrm{CO}_{3}\right)$ has also been presented in the Supplemental Information, Table S2. The size of the anion vacancies in $\mathrm{Sr}_{1.75} \mathrm{Ca}_{0.25} \mathrm{CuO}_{2}\left(\mathrm{CO}_{3}\right)$ is 3.44(3) $\AA$ (based on the distance between the $\mathrm{Cu}$ atoms in the $b$ direction), hence larger than that in $\mathrm{Ca}_{2} \mathrm{CuO}_{3}$ is (3.25(1) $\AA$ ).

$\mathrm{Sr}_{18} \mathrm{Ba}_{02} \mathrm{CuO}_{3}$ shows a larger unit cell than $\mathrm{Sr}_{2} \mathrm{CuO}_{2}\left(\mathrm{CO}_{3}\right)$, due to the substitution of $10 \%$ of the $\mathrm{Sr}^{2+}$ cations with the larger $\mathrm{Ba}^{2+}$ cations, hence larger vacancies in the crystal structure. $\mathrm{Sr}_{1.8} \mathrm{Ba}_{0.2} \mathrm{CuO}_{3}$ was obtained as single phase via solid state reaction and Rietveld refinement of the occupancies of the $\mathrm{Sr}^{2+}$ and $\mathrm{Ba}^{2+}$ cations, confirmed that $10 \%$ molar substitution of $\mathrm{Ba}^{2+}$ for $\mathrm{Sr}^{2+}$ has occurred (Figure 2 Supplemental Information). $\mathrm{Sr}_{1.8} \mathrm{Ba}_{0.2} \mathrm{CuO}_{2}\left(\mathrm{CO}_{3}\right)$ was prepared via the reaction of
$\mathrm{Sr}_{1.8} \mathrm{Ba}_{0.2} \mathrm{CuO}_{3}$ with $\mathrm{CO}_{2}$, following the same procedure devised for $\mathrm{Sr}_{2} \mathrm{CuO}_{3}$. The PXRD pattern showed that the main phase is $\mathrm{Sr}_{1.8} \mathrm{Ba}_{0.2} \mathrm{CuO}_{2}\left(\mathrm{CO}_{3}\right)$ oxycarbonate, with $\mathrm{SrCuO}_{2}$ and $\mathrm{SrCO}_{3}$ as secondary phases. A three-phase Rietveld refinement was performed using the model by Babu et al. for $\mathrm{Sr}_{2} \mathrm{CuO}_{2}\left(\mathrm{CO}_{3}\right)$, the one by Antao et al. for $\mathrm{SrCO}_{3}$, and the model by Lines et al. for $\mathrm{SrCuO}_{2}$ is shown in figure 6. Rietveld refinement data are summarised in Table S3, in the Supplemental Information. ${ }^{[39,41,42]}$

The lattice parameters were refined as $A=3.90924(5) \AA$, $c=$ $7.53570(2) \AA, V=115.162(3) \AA^{3}$ and the R-values of $R_{w p}=11.3 \%$ and $\mathrm{Rp}=8.4 \%$. The structural data of $\mathrm{Sr}_{1.8} \mathrm{Ba}_{0.2} \mathrm{CuO}_{2}\left(\mathrm{CO}_{3}\right)$ has also been presented in the Supplemental Information, Table $\mathrm{S} 3$. The size of the anion vacancies in $\mathrm{Sr}_{1.8} \mathrm{Ba}_{0.2} \mathrm{CuO}_{2}\left(\mathrm{CO}_{3}\right)$ is 3.53(2) $\AA$ (based on the distance between the $\mathrm{Cu}$ atoms in the $\mathrm{b}$ direction), hence larger than that in $\mathrm{Sr}_{2} \mathrm{CuO}_{3}$ is $(3.50(2) \AA)$.

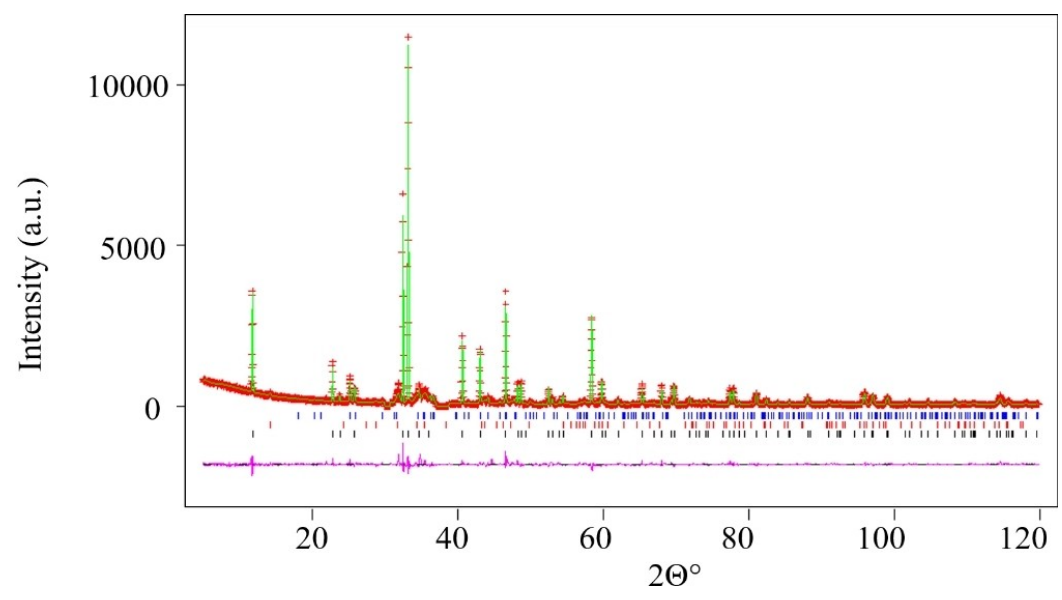

Figure 5. Rietveld refinement profile of $\mathrm{Sr}_{1.75} \mathrm{Ca}_{0.25} \mathrm{CuO}_{2}\left(\mathrm{CO}_{3}\right)$ obtained from a 90-minute reaction of $\operatorname{Sr}_{1.5} \mathrm{Ca}_{0.5} \mathrm{CuO}_{2}\left(\mathrm{CO}_{3}\right)$ under $\mathrm{CO}_{2}$. This shows the observed (red crosses), calculated (green) and difference (purple) patterns. The ticks represent $\mathrm{Sr}_{1.75} \mathrm{Ca}_{0.25} \mathrm{CuO}_{2}\left(\mathrm{CO}_{3}\right)\left(\right.$ black), $\mathrm{SrCaCuO}_{3}(\mathrm{red})$ and $\mathrm{SrCO}_{3}(\mathrm{blue})$.

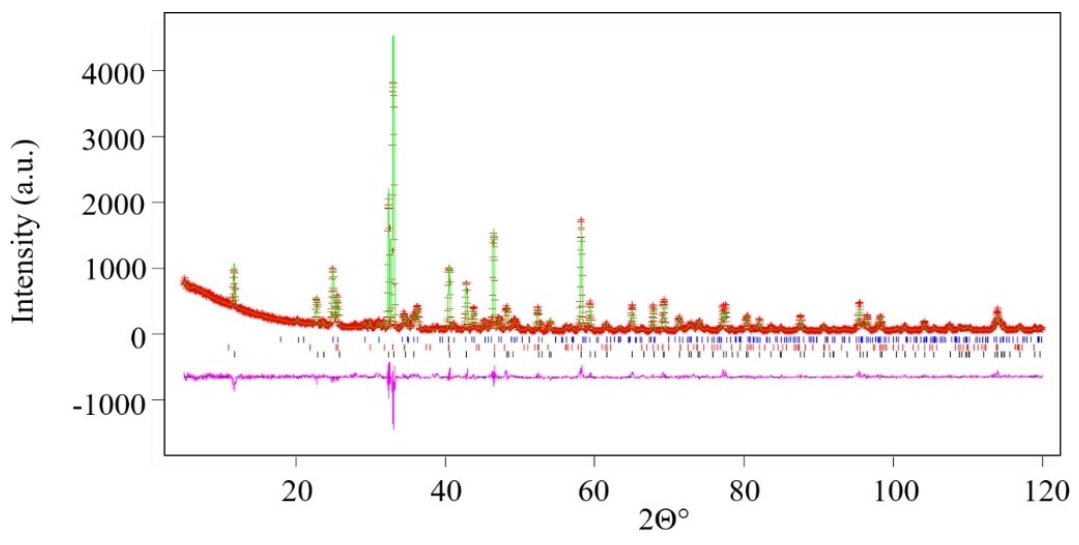

Figure 6. Rietveld refinement profile of $\mathrm{Sr}_{1.8} \mathrm{Ba}_{0.2} \mathrm{CuO}_{2}\left(\mathrm{CO}_{3}\right)$ showing the observed (red crosses), calculated (green) and difference (purple) patterns. The ticks represent $\mathrm{Sr}_{1.8} \mathrm{Ba}_{0.2} \mathrm{CuO}_{2}\left(\mathrm{CO}_{3}\right)$ (black), $\mathrm{SrCuO}_{2}$ (red) and $\mathrm{SrCO}_{3}$ (blue).

Chem. Eur. J. 2021, 27, 1-1

www.chemeurj.org 

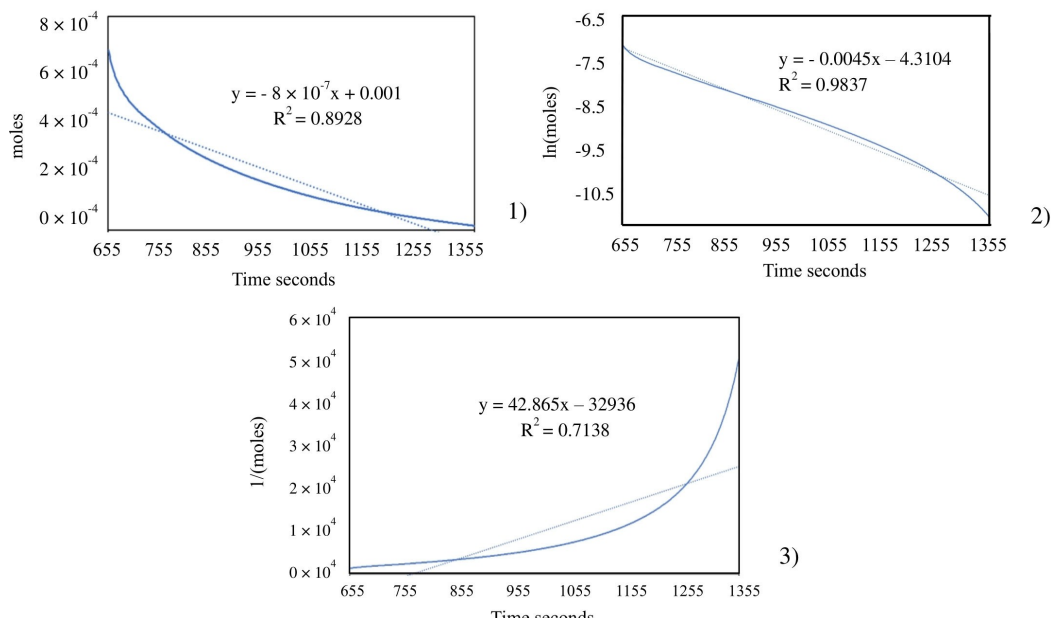

Figure 7. Three concentrations vs. time graphs, (1) moles of $\mathrm{Sr}_{2} \mathrm{CuO}_{3}$ vs. time seconds, (2) $\ln \left(\right.$ moles) $\mathrm{Sf}_{2} \mathrm{CuO}_{3}$ vs. time seconds, and (3) $1 /(\mathrm{moles})$ of $\mathrm{Sr}_{2} \mathrm{CuO}{ }_{3}$ vs. time second. Equations of trendlines and $R^{2}$ are given for each graph. The best fit $\left(R^{2}=0.9837\right)$ is obtained for a first-order kinetics.

\section{Kinetics of formation for oxide-carbonates}

Using the change in mass over time provided by the TGA curves (Figure 3), we can determine the order of reaction for the direct reaction between the starting oxides and $\mathrm{CO}_{2}$ gas, as well as reaction rate, $k$. We performed this determination for the formation of $\mathrm{Sr}_{2} \mathrm{CuO}_{2}\left(\mathrm{CO}_{3}\right), \quad \mathrm{Sr}_{1.8} \mathrm{Ba}_{0.2} \mathrm{CuO}_{2}\left(\mathrm{CO}_{3}\right)$ and $\mathrm{Sr}_{1.5} \mathrm{Ca}_{0.5} \mathrm{CuO}_{2}\left(\mathrm{CO}_{3}\right)$.

All three determinations follow the method outlined briefly here: we identified the data points on the TGA curve resulting from mass increase. In the case of $\mathrm{Sr}_{2} \mathrm{CuO}_{2}\left(\mathrm{CO}_{3}\right)$, for example, those were identified at $33.4466 \mathrm{mg}(655$ seconds $)$ to $37.6611 \mathrm{mg}$ (1355 seconds). Between these two points, the sample mass increased by $4.2145 \mathrm{mg}$ as $\mathrm{Sr}_{2} \mathrm{CuO}_{3}$ reacted with $\mathrm{CO}_{2}$ forming $\mathrm{Sr}_{2} \mathrm{CuO}_{2}\left(\mathrm{CO}_{3}\right)$. This shows that there is an increase of $4.215 \mathrm{mg}$, entirely due to $\mathrm{CO}_{2}$ insertion in 700 seconds. Using this relationship, we can infer the amount of $\mathrm{Sr}_{2} \mathrm{CuO}_{3}$ utilised at each second from the sample weight gain.

The order of reaction was determined to be $1^{\text {st }}$ by fitting a line of best fit for the relationship between the concentration of $\mathrm{Sr}_{2} \mathrm{CuO}_{3}$ vs. time (Figure 7 and Figures $\mathrm{S} 1$ and S2). The trendline of the graph can also then be used to determine a quantitative value for the rate constant $k$. Figure 7 shows three different graphs for concentration vs. time, (1) moles of $\mathrm{Sr}_{2} \mathrm{CuO}_{3}$ vs. time seconds, (2) $\ln$ (moles) of $\mathrm{Sr}_{2} \mathrm{CuO}_{3}$ vs. time seconds, and (3) 1/ (moles) of $\mathrm{Sr}_{2} \mathrm{CuO}_{3}$ vs. time seconds, along with the respective kinetic models.

The apparent first-order kinetics constant for this reaction is determined from the slope of the fit to be $k=0.0045 \mathrm{~s}^{-1}$. A firstorder kinetics model is consistent with a reaction where $\mathrm{CO}_{2}$ is constantly replenished (this is the case, due to a constant stream of fresh $\mathrm{CO}_{2}$ during the reaction) but where the oxide reaction sites are the limiting factors. Here we assume that the formation of the alkaline-earth/copper oxide-carbonate is the rate determining reaction. For all reactions we neglected the contribution from the formation of the alkaline-earth carbonates, as subtracting the weight of such carbonates would not change the slope.

The same procedure was followed for the formation reactions of $\mathrm{Sr}_{1.8} \mathrm{Ba}_{0.2} \mathrm{CuO}_{2}\left(\mathrm{CO}_{3}\right)$ and $\mathrm{Sr}_{1.5} \mathrm{Ca}_{0.5} \mathrm{CuO}_{2}\left(\mathrm{CO}_{3}\right)$ both reactions also followed first-order kinetics. Our results for the kinetic constants obtained are summarised in Table 1 below.

The reaction rates confirm that the substitution of calcium for strontium in $\mathrm{Sr}_{2} \mathrm{CuO}_{3}$ results in a lower reaction rate with $\mathrm{CO}_{2}$ and slower reaction time, compared to the full strontium equivalent.

First-principles kinetic modelling of the reaction of $\mathrm{CO}_{2}$ with $\mathrm{A}_{2-\mathrm{B}} \mathrm{B}_{\mathrm{x}} \mathrm{CuO}_{3}(\mathrm{~A}, \mathrm{~B}=\mathrm{Ca}, \mathrm{Sr}, \mathrm{Ba})$

In order to rationalise the kinetic constants measured experimentally (Table 1), we suggest that the $\mathrm{CO}_{2}$ reaction proceeds through a surface-type mechanism and therefore should be well described by a model comprising a layer of alkaline-earth oxide and where the copper layer plays only a minor part. Indeed, a surface-like reaction occurs in $\mathrm{A}_{2} \mathrm{CuO}_{3}$ because "voids" are present in their crystal structure. At reaction temperature (approx. $1000^{\circ} \mathrm{C}$ ), $\mathrm{CO}_{2}$ gas will enter these voids and binds to the oxide anions to form the carbonate. This then means that an investigation of the reaction of $\mathrm{CO}_{2}$ with an $\mathrm{AO}$ oxide surface should be a reasonable proxy for the formation of $A_{2-x^{-}}$ $\mathrm{B}_{\mathrm{x}} \mathrm{CuO}_{2}\left(\mathrm{CO}_{3}\right)$.

\begin{tabular}{|c|c|c|c|}
\hline Oxide & $\mathrm{Sr}_{2} \mathrm{CuO}_{3}$ & $\mathrm{Sr}_{1.8} \mathrm{Ba}_{0.2} \mathrm{CuO}_{3}$ & $\mathrm{Sr}_{1.5} \mathrm{Ca}_{0.5} \mathrm{CuO}_{3}$ \\
\hline $\mathrm{k} / \mathrm{s}^{-1}$ & 0.0045 & 0.0048 & 0.0016 \\
\hline
\end{tabular}


There are already a number of studies that investigated the reaction of $\mathrm{CO}_{2}$ with $\mathrm{AO}(\mathrm{A}=\mathrm{Ca}, \mathrm{Sr}$ and $\mathrm{Ba})$ oxides (Karlsen et al. and Schneider) ${ }^{[18,47]}$ Both of those studies use molecular functionals (PW91 or B3LYP), instead in our study we use PBE, which has traditionally been used for describing processes occurring at surfaces. While this choice might slightly disadvantage the description of molecular $\mathrm{CO}_{2}$, it has nevertheless been shown to give realistic surface binding energies. ${ }^{[48]}$ Furthermore, compounds showing perovskite-like structure have been shown to be prone to $A$ enrichment on the surface compared to the bulk, with this segregation affecting reactivity with gas phases. ${ }^{[49]}$

The optimised structure of $\mathrm{CO}_{2}$ chemisorbed on a $\mathrm{SrO}$ "surface" (see "Theoretical approach to study the solid-gas reactions" in the experimental section for a full description of the surface model) is shown in Figure 8. We note that this structure is in very good agreement with the previous studies of Schneider and Karlsen et al. ${ }^{[18,47]}$ Our results for the bond lengths, $\mathrm{O}-\mathrm{C}-\mathrm{O}$ bond angle and adsorption energy for all three oxides $(A=S r, C a$ and $B a)$ are summarised in Table 2 , along with the results obtained with different functionals by Schneider and Karlsen et al. ${ }^{[18,47]}$. The adsorption energy was determined as the difference between the optimised $\mathrm{CO}_{2}$ and cluster energy separately to that of the surface-carbonate end-product.

We see that, for all oxides, the $\mathrm{O}_{\mathrm{s}}-\mathrm{C}$ distances computed with PBE are similar to those obtained with PW91, as expected since those two functionals are similar, and slightly shorter than the B3LYP results of Karlsen. This effectively puts our PBE values in between those of the two approaches. We see a similar trend

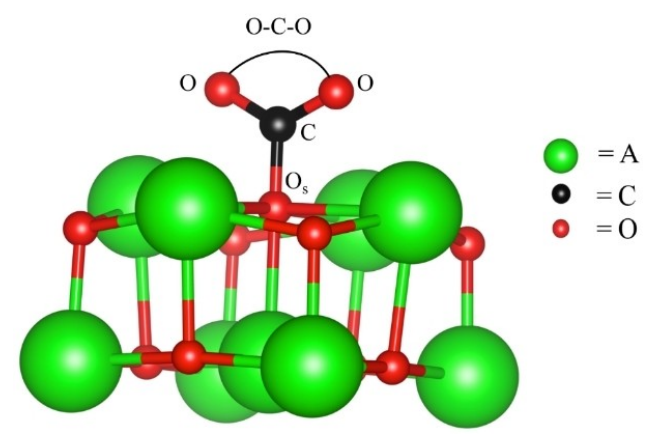

Figure 8. The optimised carbonate on the $\mathrm{AO}(\mathrm{A}=\mathrm{Ca}$, $\mathrm{Sr}$ and $\mathrm{Ba})$ cluster. The areas where the $\mathrm{O}-\mathrm{C}-\mathrm{O} O$ angles and $\mathrm{C}-\mathrm{O}_{S}$ bond lengths are measures are shown. for the $\mathrm{C}-\mathrm{O}$ distances, where this time the B3LYP values are shorter and the PW91 values are longer, with our PBE results in between the two. Finally, the $\mathrm{O}-\mathrm{C}-\mathrm{O}$ angle for all cases is slightly smaller with PBE than with PW91 or B3LYP.

Table 2 shows that the adsorption energies we computed using PBE again are in-between the PW91 results of Schneider and the B3LYP data of Karlsen et al. ${ }^{[47]}$ As expected, our GGA functional delivers results closer to the other GGA functional (PW91) rather than the hybrid B3LYP approach. Overall, our results are fully compatible with the published literature for both structural and energetic data.

\section{Kinetic model}

In order to gain some insights into the molecular mechanism of the reaction kinetics observed when varying the nature of the alkaline-earth metal (A), we propose the approach below. We assume reversible kinetics and therefore the kinetics of each reaction can be modelled by an Arrhenius-type equation:

$$
k_{x}=\operatorname{Aexp}\left(-\frac{E_{x}}{T}\right)
$$

Where $E_{x}$ is the adsorption energy of $\mathrm{CO}_{2}$ on the oxide surface for $A=x, A$ is the usual pre-exponential factor related to the probability of collision and $T$ is the reaction temperature. To confirm the reversibility assumption or model, we reacted the oxycarbonates in air at the same conditions of time and temperature. The original oxides resulted from this reaction, thus confirming reversibility. This model was originally derived for surface adsorption kinetics, but it seems appropriate to use this here as the adsorption of $\mathrm{CO}_{2}$ onto the reaction site is likely to be the rate-determining step.

Since the reactions all involve the same reactant $\left(\mathrm{CO}_{2}\right)$ and the reaction mechanism is the same (i.e., insertion into the solid), we assume that $A$ is the same regardless of the nature of the alkaline-earth metal. This enables us to derive a simple relation between the kinetic constants of two reactions. By combining equation (1) for two different oxide surfaces in their logarithmic form, we obtain:

$$
\ln k_{1}=\ln A-\frac{E_{1}}{T} \text { and } \ln k_{2}=\ln A-\frac{E_{2}}{T}
$$

\begin{tabular}{|c|c|c|c|c|c|}
\hline Surface & Functional & $\mathrm{O}_{s}-\mathrm{C}$ distance $[\AA]$ & $\mathrm{C}-\mathrm{O}$ distance $[\AA]]$ & $\mathrm{O}-\mathrm{C}-\mathrm{O}$ angle $\left[{ }^{\circ}\right]$ & Adsorption energy $\left[\mathrm{kJ} \mathrm{mol}^{-1]}\right.$ \\
\hline \multirow[t]{3}{*}{$\mathrm{SrO}$} & PBE (This work) & 1.392 & 1.267 & 127.0 & -163 \\
\hline & PW91 (Schneider) & 1.370 & 1.276 & 127.5 & -188 \\
\hline & B3LYP (Karlsen) & 1.460 & 1.240 & 132.0 & -123 \\
\hline \multirow[t]{3}{*}{$\mathrm{CaO}$} & PBE (This work) & 1.413 & 1.262 & 128.6 & -124 \\
\hline & PW91 (Schneider) & 1.384 & 1.270 & 129.1 & -130 \\
\hline & B3LYP (Karlsen) & 1.490 & 1.230 & 134.0 & -87 \\
\hline \multirow[t]{3}{*}{$\mathrm{BaO}$} & PBE (This work) & 1.374 & 1.272 & 125.6 & -193 \\
\hline & PW91 (Schneider) & 1.358 & 1.282 & 126.0 & -226 \\
\hline & B3LYP (Karlsen) & 1.440 & 1.240 & 130.4 & -158 \\
\hline
\end{tabular}

Chem Eur. J. 2021, 27, 1-11 
thus:

$\ln k_{1}-\ln k_{2}=\ln A-\frac{E_{1}}{T}-\left(\ln A-\frac{E_{2}}{T}\right)$

leading to:

$\ln k_{1}-\ln k_{2}=-\frac{E_{1}}{T}+\frac{E_{2}}{T}=\frac{E_{2}-E_{1}}{T}=\frac{\Delta E}{T}$

where $k_{1}$ and $k_{2}$ are the kinetic constants for each reaction at temperature $T$ and $\Delta E$ is the difference in adsorption energy of $\mathrm{CO}_{2}$ onto the respective oxide surface models.

Using the results from Table 2, we can therefore determine a relation between the logarithms of the kinetic constants from first principles. However, as some of the oxides are actually mixed oxides, we use their stoichiometric composition to weight their respective adsorption energy, $E_{A_{x} B_{y} O}=\frac{x}{x+y} E_{A O}+\frac{y}{x+y} E_{B O}$. Our results are summarised in Table 3.

We use the computed weighted energies $E_{A_{x} B_{y} O}$ from Table 3, to calculate the predicted Reactive adsorption energy difference $(\Delta E)$ with the kinetic model described earlier (see Equation (2)). The results obtained are shown in Table 4, where we also compute the same values using the kinetic data measured during the reactions.

We observe that there is a strong qualitative agreement between our surface kinetics model and the experimental observations. In particular, both the sign and the magnitude of the energy difference are well predicted for all reactions. For example, we correctly predict that $\mathrm{Sr}_{1.8} \mathrm{Ba}_{0.2} \mathrm{CuO}_{3}$ reacts faster than the pure strontium copper oxide, while $\mathrm{Sr}_{1.5} \mathrm{Ca}_{0.5} \mathrm{CuO}_{3}$ reacts much slower than the other two compounds. This validates our initial assumption of a reaction that follows surface adsorption kinetics. Our model could be useful when predicting the kinetics of other insertion reactions in solids with vacancies in their crystal structure.

\begin{tabular}{|c|c|c|c|c|}
\hline $\mathrm{T}=1273 / \mathrm{K}$ & $\mathrm{k} / \mathrm{s}^{-1}$ & $\ln (\mathrm{k})$ & $\begin{array}{l}\text { Binary oxides } \\
E_{A O} / \mathrm{kJ} \mathrm{mol}^{-1}\end{array}$ & $\begin{array}{l}\text { Weighted energies } \\
E_{A_{x} B_{y} \mathrm{O}} / \mathrm{kJ} \mathrm{mol}^{-1}\end{array}$ \\
\hline $\mathrm{Sr}_{2} \mathrm{CuO}_{3}$ & 0.0045 & -5.4037 & -163 & \\
\hline $\mathrm{Sr}_{1.8} \mathrm{Ba}_{0.2} \mathrm{CuO}_{3}$ & 0.0048 & -5.3391 & -193 & -166 \\
\hline $\mathrm{Sr}_{1.5} \mathrm{Ca}_{0.5} \mathrm{CuO}_{3}$ & 0.0016 & -6.4378 & -124 & -153 \\
\hline
\end{tabular}

Reaction of $\mathrm{Ba}_{2} \mathrm{PdO}_{3}$ with $\mathrm{CO}_{2}$

$\mathrm{Ba}_{2} \mathrm{PdO}_{3}$ is isostructural to $\mathrm{Sr}_{2} \mathrm{CuO}_{3}$ and shows one-dimensional $\mathrm{Pd}-\mathrm{O}$ chains with $\mathrm{Pd}^{2+}$ coordinated in a square-planar fashion. $\mathrm{Ba}_{2} \mathrm{PdO}_{3}$ was therefore used to test the wider applicability of the direct reaction of $\mathrm{CO}_{2}$ with compounds isostructural with $\mathrm{Sr}_{2} \mathrm{CuO}_{3}$. Similarly, to $\mathrm{Sr}_{2} \mathrm{CuO}_{3}, \mathrm{Ba}_{2} \mathrm{PdO}_{3}$ was also reported to undergo fluorination to form the oxide-fluoride $\mathrm{Ba}_{2} \mathrm{PdO}_{2} \mathrm{~F}_{2} \cdot{ }^{[16,17]}$

$\mathrm{Ba}_{2} \mathrm{PdO}_{3}$ was reacted with $\mathrm{CO}_{2}$ in identical conditions as $\mathrm{Sr}_{2} \mathrm{CuO}_{3}$. This resulted in a three-phase sample with $\mathrm{Ba}_{11} \mathrm{Pd}_{11} \mathrm{O}_{20}\left(\mathrm{CO}_{3}\right)_{2}$ as the main phase, $\mathrm{BaCO}_{3}$ and $\mathrm{Pd}$ metal. The Rietveld refinement of the sample is shown in Figure 9. The parameters derived from Rietveld refinement are listed in Table S4.

$\mathrm{Ba}_{11} \mathrm{Pd}_{11} \mathrm{O}_{20}\left(\mathrm{CO}_{3}\right)_{2}$ was reported by Crooks and Weller and has been labelled as " $\mathrm{BaPdO}_{2}$ ", due to the $1: 1: 2$ ratio between the cations and anion. In $\mathrm{Ba}_{11} \mathrm{Pd}_{11} \mathrm{O}_{20}\left(\mathrm{CO}_{3}\right)_{2}, \mathrm{Pd}$ maintains its square planar coordination as in the starting oxide $\mathrm{Ba}_{2} \mathrm{PdO}_{3}$. Hence, the insertion of $\mathrm{CO}_{2}$ changes the crystal structure and the chemical composition, however, the strong stability of the $\mathrm{Pd}^{2+}$ cation in square-planar coordination prevents a structural rearrangement identical to the one occurring for $\mathrm{Sr}_{2} \mathrm{CuO}_{3}$. Similarly, $\mathrm{Pd}^{2+}$ maintained its original square-planar coordination when undergoing fluorination from $\mathrm{Ba}_{2} \mathrm{PdO}_{3}$ to $\mathrm{Ba}_{2} \mathrm{PdO}_{2} \mathrm{~F}_{2} \cdot{ }^{[17]}$

Rietveld refinements used the X-ray diffraction data for the models $\mathrm{Ba}_{11} \mathrm{Pd}_{11} \mathrm{O}_{20}\left(\mathrm{CO}_{3}\right)_{2}{ }^{[50]} \mathrm{BaCO}_{3}{ }^{[51]}$ and $\mathrm{Pd}$ metal. ${ }^{[52]}$ The refinement calculated $\mathrm{R}_{\mathrm{wp}}=11.4$ and $\chi^{2}=3.981$ and showed in the terms of the weight fraction $\%, \mathrm{Ba}_{11} \mathrm{Pd}_{11} \mathrm{O}_{20}\left(\mathrm{CO}_{3}\right)_{2}(50 \%)$, $\mathrm{BaCO}_{3}(42 \%)$ and $\mathrm{Pd}$ metal (8\%). The structural data of $\mathrm{Ba}_{11} \mathrm{Pd}_{11} \mathrm{O}_{20}\left(\mathrm{CO}_{3}\right)_{2}$ has also been presented in the Supplemental Information, Table $\mathrm{S} 4$.

\section{Conclusion}

This works explores the utilisation of $\mathrm{CO}_{2}$ as a reagent for the modification of the crystal structure of solids. Modifying the crystal structure of solids is a chemical tool to tailor their properties towards specific applications, and we demonstrate that structure tailoring via solid-gas reaction with $\mathrm{CO}_{2}$ could be added to this toolbox. Selected mixed metal oxides were reacted with $\mathrm{CO}_{2}$ and led to the formation of oxide-carbonates with modified crystal structures. The selected oxides were $\mathrm{Sr}_{2} \mathrm{CuO}_{3}, \mathrm{Sr}_{1.8} \mathrm{Ba}_{0.2} \mathrm{CuO}_{3}, \mathrm{Sr}_{1.5} \mathrm{Ca}_{0.5} \mathrm{CuO}_{3}$ and $\mathrm{Ba}_{2} \mathrm{PdO}_{3}$. They are all isostructural and showing anion-deficient $\mathrm{K}_{2} \mathrm{NiF}_{4}$ structure and were chosen because their crystal structure shows vacancies

\begin{tabular}{|c|c|c|c|}
\hline$\Delta E=\left(\ln k_{1}-\ln k_{2}\right) \cdot T$ & Reaction $2\left(k_{2}\right)$ & & \\
\hline $\begin{array}{l}\text { Reaction } 1\left(k_{1}\right) \\
\mathrm{Sr}_{2} \mathrm{CuO}_{3} \stackrel{\mathrm{CO}_{2}}{\longrightarrow} \mathrm{Sr}_{2} \mathrm{CuO}_{2} \mathrm{CO}_{3}\end{array}$ & 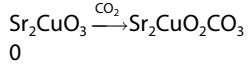 & $\begin{array}{l}\mathrm{Sr}_{1.8} \mathrm{Ba}_{0.2} \mathrm{CuO}_{3} \stackrel{\mathrm{CO}_{2}}{\longrightarrow} \mathrm{Sr}_{1.8} \mathrm{Ba}_{0.2} \mathrm{CuO}_{2} \mathrm{CO}_{3} \\
-0.68(-3.00)\end{array}$ & $\begin{array}{l}\mathrm{Sr}_{1.5} \mathrm{Ca}_{0.5} \mathrm{CuO}_{3} \stackrel{\mathrm{CO}_{2}}{\longrightarrow} \mathrm{Sr}_{1.5} \mathrm{Ca}_{0.5} \mathrm{CuO}_{2} \mathrm{CO}_{3} \\
+10.94(+9.75)\end{array}$ \\
\hline $\mathrm{Sr}_{1.8} \mathrm{Ba}_{0.2} \mathrm{CuO}_{3} \stackrel{\mathrm{CO}_{2}}{\longrightarrow} \mathrm{Sr}_{1.8} \mathrm{Ba}_{0.2} \mathrm{CuO}_{2} \mathrm{CO}_{3}$ & $+0.68(+3.00)$ & 0 & $+11.63(+12.75)$ \\
\hline $\mathrm{Sr}_{1.5} \mathrm{Ca}_{0.5} \mathrm{CuO}_{3} \stackrel{\mathrm{CO}_{2}}{\longrightarrow} \mathrm{Sr}_{1.5} \mathrm{Ca}_{0.5} \mathrm{CuO}_{2} \mathrm{CO}_{3}$ & $-10.94(-9.75)$ & $-11.63(-12.75)$ & 0 \\
\hline
\end{tabular}




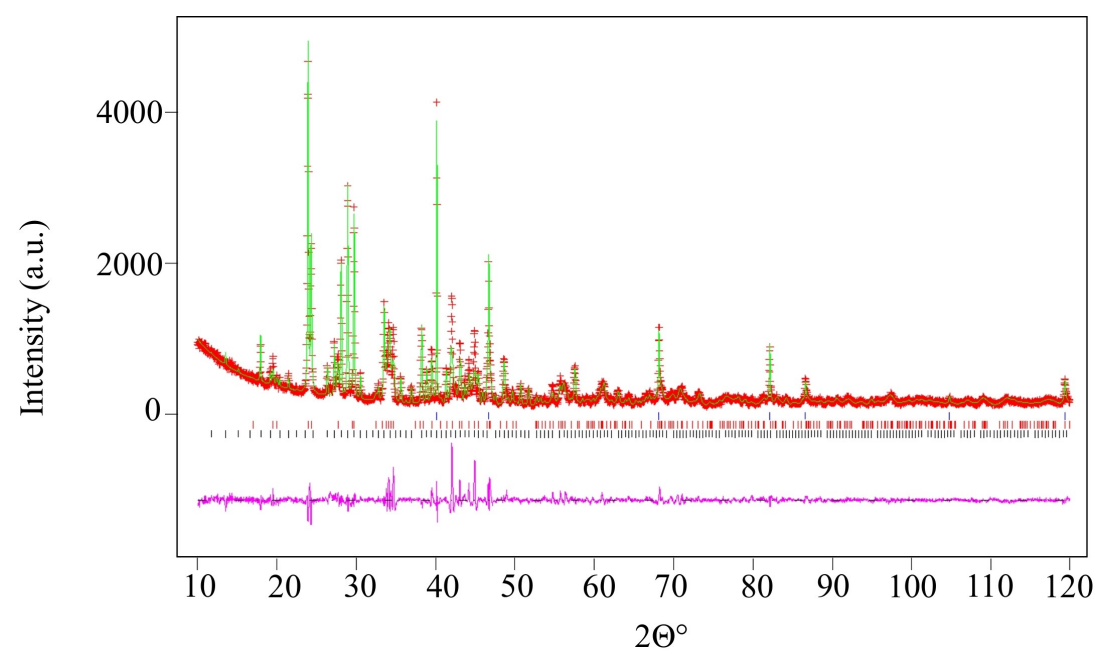

Figure 9. Rietveld refinement pattern of $\mathrm{Ba}_{2} \mathrm{PdO}_{3}$ after reacting with $\mathrm{CO}_{2}$, showing the observed (red crosses), calculated (green) and difference (purple) patterns. The ticks represent $\mathrm{Ba}_{11} \mathrm{Pd}_{11} \mathrm{O}_{20}\left(\mathrm{CO}_{3}\right)_{2}$ (black), $\mathrm{BaCO}_{3}$ (red) and $\mathrm{Pd}$ metal (blue).

with potential to be host sites for $\mathrm{CO}_{2}$. The actual chemical reactions were designed in a way that prevented as much as possible the formation of the favourable alkaline-earth carbonates as secondary phases. The oxide carbonates $\mathrm{Sr}_{2} \mathrm{CuO}_{2}\left(\mathrm{CO}_{3}\right)$, $\mathrm{Sr}_{1.8} \mathrm{Ba}_{0.2} \mathrm{Cu} \mathrm{O}_{2}\left(\mathrm{CO}_{3}\right), \mathrm{Sr}_{1.75} \mathrm{Ca}_{0.25} \mathrm{Cu} \mathrm{O}_{2}\left(\mathrm{CO}_{3}\right)$ and $\mathrm{Ba}_{11} \mathrm{Pd}_{11} \mathrm{O}_{22}\left(\mathrm{CO}_{3}\right)_{2}$ were obtained and showed filled $\mathrm{K}_{2} \mathrm{NiF}_{4}$-type structure, indicating that $\mathrm{CO}_{2}$ can be used as a reagent to modify the crystal structure of oxides, as well as prepare oxide carbonates.

We proposed a simple model for the kinetics of the reactions between the cuprates and $\mathrm{CO}_{2}$ based on calculations of the adsorption energy of $\mathrm{CO}_{2}$ on the surface of the binary alkaline earth metal oxides. We obtained near-quantitative agreement with the kinetics determined for the apparent reactions.

Some initial guidelines can be evinced for the application of $\mathrm{CO}_{2}$ as crystal structure modifier to a wider range of materials as well as the preparation of novel oxide-carbonates. The $\mathrm{CO}_{2}$ molecules insert into the vacancies within the crystal structure of the parent compounds and links with an oxide to give the carbonate anion. Hence, the starting materials should be oxides and their crystal structure must show voids to host the $\mathrm{CO}_{2}$. Furthermore, we suggest that these vacancies need to be of appropriate size to host $\mathrm{CO}_{2}$, the kinetic diameter of which is $3.3 \AA$.

\section{Acknowledgements}

The authors would like to thank the University of Hull for funding a PhD studentship the EU FP7 Marie Curie Network CAPZEO and the EU H2020 MSCA RISE ATMOS. We also acknowledge the Viper High Performance Computing facility of the University of Hull and its support team.

Chem. Eur. J. 2021, 27, 1-11

www.chemeurj.org

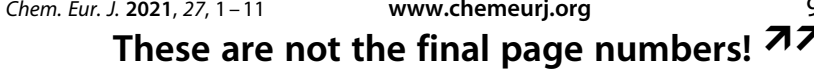

\section{Conflict of Interest}

The authors declare no conflict of interest.

\section{Data Availability Statement}

The data that support the findings of this study are available from the corresponding author upon reasonable request.

Keywords: carbon dioxide fixation · intercalation · main groups elements $\cdot$ perovskite phases $\cdot$ transition metals

[1] J. G. Olivier, G. Janssens-Maenhout, M. Muntean, J. A. H. W. Peters, Trends in Global $\mathrm{CO}_{2}$ Emissions: 2014 Report, PBL Netherlands Environmental Assessment Agency, The Hague, 2014.

[2] P. Nejat, F. Jomehzadeh, M. Taheri, M. Gohari, M. Majid, Renewable Sustainable Energy Rev. 2015, 43, 843-862.

[3] J. Wang, L. Huang, R. Yang, Z. Zhang, J. Wu, Y. Gao, Q. Wang, D. O'Hare Z. Zhong, Energy Environ. Sci. 2014, 7, 3478-3518.

[4] R. Xu, W. Pang, J. Yu, Q. Huo, J. Chen, Chemistry of Zeolites and Related Porous Materials: Synthesis and Structure, Wiley, Clementi Singapore, 2007.

[5] J. Čejka, A. Corma, S. Zones, Zeolites and Catalysis: Synthesis, Reactions and Applications, Wiley-VCH, New York USA, 2010.

[6] N. Nijem, Y. J. Chabal, Comment. Inorg. Chem. 2014, 34, 78-102.

[7] D. Danaci, R. Singh, P. Xiao, P. A. Webley, Chem. Eng. J. 2015, 280, 486493

[8] J. Blamey, E. J. Anthony, J. Wang, I. P. S. Fennel, Prog. Energ. Combust. 2010, 36, 260-279.

[9] W. Liu, H. An, C. Qin, J. Yin, G. Wang, F. B. M. Xu, Energy Fuels 2012, 26, 2751-2767.

[10] R. C. Lobo, F. C. Berry, C. Greaves, J. Solid State Chem. 1990, 88, 513-519.

[11] Z. Hiroi, M. Takano, M. Azuma, Y. Takeda, Nature 1993, 364, 315-317.

[12] C. Greaves, M. G. Francesconi, Curr. Opin. Solid St. M. 1998, 3, 132-136.

[13] M. G. Francesconi, P. R. Slater, J. P. Hodges, C. Greaves, P. P. Edwards, M. Al-Mamouri, M. Slaski, J. Solid State Chem. 1998, 135, 17-27.

[14] K. Adachi, S. Tatsuki, T. Sugano, T. Tokiwa-Yamamoto, A. Tanabe, Phys. C Supercond. 2000, 334, 87-94.

[15] P. R. Slater, J. P. Hodges, M. G. Francesconi, P. P. Edwards, C. Greaves, I. Gameson, M. Slaski, Phys. C. 1995, 253, 16-22. 
[16] Y. Laligant, A. Le Bail, G. Ferey, M. Hervieu, B. Raveau, A. Wilkinson, A. K. Cheetham, Eur. J. Solid State Inorg. Chem. 1988, 25, 237-247.

[17] T. Baikie, E. L. Dixon, J. F. Rooms, N. A. Young, M. G. Francesconi, Chem Commun. 2003, 2003, 1580-1581.

[18] W. F. Schneider, J. Phys. Chem. A 2004, 108, 273-282.

[19] E. J. Karlsen, M. A. Nygren, L. G. M. Pettersson, J. Phys. Chem. B 2003 , $107,7795-7802$.

[20] Y. Duan, D. C. Sorescu, J. Chem. Phys. 2010, 133, 074508-074519.

[21] B. Zhang, Y. Duan, K. Johnson, J. Chem. Phys. 2012, 136, 064516 064530.

[22] P. R. Slater, P. P. Edwards, C. Greaves, I. Gameson, M. G. Francesconi, J. P. Hodges, M. Al-Mamouri, M. Slaski, Phys. C Supercond. 1995, 241, 151157.

[23] T. Baikie, N. A. Young, M. G. Francesconi, Prog. Solid State Chem. 2007, 35, 265-279.

[24] HighScore Plus (3.0e (3.0.5)), Almelo, The Netherlands, n.d.

[25] A. C. Larson, R. B. Von Dreele, B. H. Toby, General Structure Analysis System (GSAS), Almelo, The Netherlands, 2004.

[26] B. H. Toby, J. Appl. Crystallogr. 2001, 34, 210-213.

[27] C. J. Howard, J. Appl. Crystallogr. 1982, 15, 615-620.

[28] P. Thompson, D. E. Cox, J. B. Hastings, J. Appl. Crystallogr. 1987, 20, 7983.

[29] F. Neese, Wiley Interdiscip. Rev.: Comput. Mol. Sci. 2012, 2, 73-78.

[30] F. Neese, J. Comput. Chem. 2003, 24, 1740-1747.

[31] J. P. Perdew, K. Burke, M. Ernzerhof, Phys. Rev. Lett. 1996, 77, 3865-3868.

[32] F. Weigend, R. Ahlrichs, Phys. Chem. Chem. Phys. 2005, 7, 3297-3305.

[33] F. Weigend, Phys. Chem. Chem. Phys. 2006, 8, 1057-1065.

[34] S. Grimme, J. Antony, S. Ehrlich, H. Krieg, J. Chem. Phys. 2010, 132, 154104-154104-19.

[35] S. Grimme, S. Ehrlich, L. Goerigk, J. Comput. Chem. 2011, 32, 1456-1465.

[36] W. Gerlach, Zeitschr. Phys. 1922, 9, 184-192.
[37] T. G. Narendra Babu, D. J. Fish, C. Greaves, J. Mater. Chem. 1991, 1, 677679.

[38] Y. Miyazaki, H. Yamane, T. Kajitani, T. Oku, K. Hiraga, Y. Morii, K. Fuchizaki, S. Funahashi, T. Hirai, Phys. C. 1992, 191, 434-440.

[39] S. M. Antao, I. Hassan, Can. Miner. 2009, 47, 1245-1255.

[40] D. R. Lines, M. T. Weller, D. B. Currie, D. M. Ogborne, Mater. Res. Bull. 1991, 26, 323-331.

[41] J. R. Li, R. Kuppler, H. C. Zhou, Chem. Soc. Rev. 2009, 38, 1477-1504.

[42] E. M. Kopnin, A. T. Matveev, P. S. Salamakha, A. Sato, Phys. C 2003, 384, 163-168.

[43] S. M. Antao, I. Hassan, Can. Mineral. 2009, 47, 1245-1255.

[44] D. R. Lines, M. T. Weller, D. B. Currie, D. M. Ogbome, Mater. Res. Bull. 1991, 26, 323-331.

[45] C. J. Howard, J. Appl. Crystallogr. 1982, 15, 615-620.

[46] P. Thompson, D. E. Cox, J. B. Hastings, J. Appl. Crystallogr. 1987, 20, 7983.

[47] E. J. Karlsen, M. A. Nygren, L. G. M. Pettersson, J. Phys. Chem. B 2003 $107,7795-7802$.

[48] J. Wellendorff, T. L. Silbaugh, D. Garcia-Pintos, J. K. Nørskov, T. Bligaard, F. Studt, C. T. Campbell, Surf. Sci. 2015, 640, 36-44.

[49] B. Koo, K. Kim, J. K. Kim, H. Kwon, J. W. Han, W. C. Jung, Joule 2018, 2 1476-1499.

[50] R. J. Crooks, M. T. Weller, J. Solid State Chem. 1997, 128, 220-227.

[51] J. P. R. de Villiers, Am. Mineral. 1971, 56, 758-767.

[52] E. A. Owen, E. L. Yates, Philos. Mag. 1933, 15, 472-488.

Manuscript received: October 5, 2021

Version of record online: 


\section{RESEARCH ARTICLE}

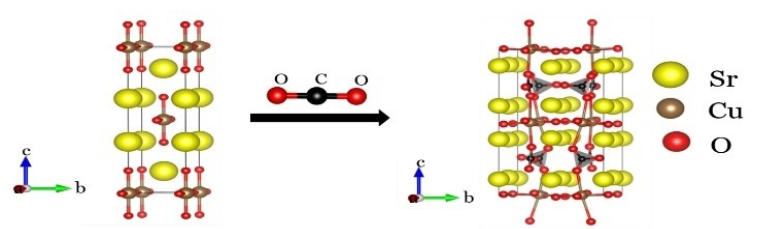

$\mathrm{CO}_{2}$ is abundant and free but environmentally unfriendly. It is also unreactive, hence re-purposing can be a challenge. This research article describes how $\mathrm{CO}_{2}$ can be used as a useful reagent towards the preparation and/or chemical and structural modification of inorganic solids. This
M. J. Bennett, I. Dobson, D. M. Benoit*, M. G. Francesconi*

$1-11$

Utilisation of $\mathrm{CO}_{2}$ as "Structure Modifier" of Inorganic Solids approach is of wide application hence, in the future, it may become part of a toolbox of methods to reduce the environmental impact of $\mathrm{CO}_{2}$. Utilisation of Carbon Dioxide as "Structure Modifier" of Inorganic Solids (D. M. Benoit, M. G. Francesconi et al.)

\section{\#\# SPACE RESERVED FOR IMAGE AND LINK}

Share your work on social media! Chemistry - A European Journal has added Twitter as a means to promote your article. Twitter is an online microblogging service that enables its users to send and read short messages and media, known as tweets. Please check the pre-written tweet in the galley proofs for accuracy. If you, your team, or institution have a Twitter account, please include its handle@username. Please use hashtags only for the most important keywords, such as \#catalysis, \#nanoparticles, or \#proteindesign. The ToC picture and a link to your article will be added automatically, so the tweet text must not exceed 250 characters. This tweet will be posted on the journal's Twitter account (follow us@ChemEurJ) upon publication of your article in its final (possibly unpaginated) form. We recommend you to re-tweet it to alert more researchers about your publication, or to point it out to your institution's social media team.

Please check that the ORCID identifiers listed below are correct. We encourage all authors to provide an ORCID identifier for each coauthor. ORCID is a registry that provides researchers with a unique digital identifier. Some funding agencies recommend or even require the inclusion of ORCID IDs in all published articles, and authors should consult their funding agency guidelines for details. Registration is easy and free; for further information, see http:// orcid.org/.

I. Dobson

M. J. Bennett

D. M. Benoit http://orcid.org/0000-0002-7773-6863

M. G. Francesconi http://orcid.org/0000-0002-0124-2197 